\title{
Memoria colectiva y relaciones de género: ¿Prácticas de dominación o resistencia?
}

\author{
- Isabel Piper Shafir * \\ UNIVERSIDAD DE ARTES Y CIENCIAS SOCIALES, ARCIS \\ Instituto Latinoamericano de Salud Mental y Derechos Humanos, ILAS
}

\section{Haciendo memoria}

La mayoría de quienes estamos aquí venimos de países que han vivido años de conflictos violentos: guerras, enfrentamientos armados, dictaduras militares y otras formas de violencia institucionalizada que han afectado a nuestras sociedades de manera importante.

En Chile, la dictadura de Pinochet ha sido narrada y explicada de muchas maneras, construyendo distintas posiciones interpretativas en este ejercicio. Las voces y los silencios, los recuerdos y los olvidos han contribuido a producir las memorias de este período de nuestra historia. La heterogeneidad de significados ha sido vivida, al mismo tiempo, como un conflicto y como un obstáculo para su resolución, llevando a los distintos grupos implicados a defender su propia interpretación de los acontecimientos.

Durante la dictadura, la institucionalidad vigente niega la existencia de violaciones a los derechos humanos y de la persecución política. En caso de ser

- Ponencia presentada al seminario internacional Educar desde la memoria. Experiencias pedagógicas para la paz, la democracia y la equidad de género, organizado en junio de 2001 por Las Dignas y la Asociación Pro Búsqueda de Niños y Niñas Desaparecidos. 
evidenciada y reconocida la existencia de la violencia por parte de los aparatos del Estado hacia los dirigentes políticos, es justificada como acciones necesarias en estado de guerra, o bien, como acciones de seguridad y defensa ante la violencia terrorista. Con estas omisiones y justificaciones se construye la historia oficial. Esa es la que aparece en los libros de texto y es lo que aprenden las niñas y niños en las escuelas. (Piper, 1999)

Tanto el silencio y el ocultamiento de la violencia de Estado, como la permanente recodificación de estos hechos como un costo necesario e inevitable, favorecen la negación de la existencia de la violación de los derechos de las personas. Frente a esto, los grupos de afectados y las personas ligadas a la defensa de los derechos humanos alzaron sus voces denunciando lo ocurrido. Así, "a nivel nacional e internacional, la denuncia pasó a ser el instrumento fundamental en la defensa de los derechos humanos. Durante muchos años, permitió atravesar la barrera del silencio respecto a las situaciones de horror, con el propósito de enfrentar activamente la incredulidad, la indiferencia y la negación desde una parte importante de la población" (Becker y col., p. 22). La defensa de la verdad de lo ocurrido se transformó en una importante bandera de lucha, buscando, entre otras cosas, dejar un registro para que, cuando las condiciones políticas cambiaran, estas verdades fueran asumidas colectivamente. (Piper, 1999)

A medida que se construyen las condiciones sociales y políticas de credibilidad de dichas denuncias; a medida que se acerca y posteriormente se desarrolla el proceso de transición a la democracia, las distintas reconstrucciones del pasado van adquiriendo distinta fuera y, algunas de ellas, en función de una compleja red de relaciones de poder, adquieren efecto de verdad. La polémica de la omisión versus el esclarecimiento de los crímenes de la dictadura, se transforma en una polémica que plantea la voluntad de ciertos sectores sociales de olvidar las violaciones a los derechos humanos ocurridas durante el régimen militar, en contraposición con la voluntad de las víctimas y sectores ligados a la defensa de los derechos humanos que plantean la necesidad de recordar.

Algunos sectores políticos parecían esperar que se iniciara "el olvido, como si fuese posible lograr que se extinguiera el problema como efecto del transcurso del tiempo. (...) Los que proponían soluciones enfatizando la necesidad de recordar, de mantener la memoria —el "no olvido"-partían del supuesto que el problema no se extinguiría con el tiempo, sino que mantendría su potencial traumático. (...) En los años siguientes, desde el final del régimen militar, parecía ser que la solución de los conflictos políticos derivados de las violaciones de derechos humanos del pasado dependía casi totalmente de operaciones psicológicas como "olvidar" o "recordar" (Kovalsky y Lira, en Lira y Piper, 1997 (1), pp. 25-26)

Olvidar o recordar se construyen como posiciones antagónicas, en las cuales el olvido es una estrategia propuesta por los partidarios del régimen militar, 
mientras el recuerdo es planteado como una opción moral y una alternativa de resistencia frente a los intentos de sectores de la sociedad por imponer sus versiones oficiales. Esta oposición ha sido comentada en numerosas ocasiones por personajes de diversos ámbitos, y una afirmación ampliamente compartida es que el olvido ha sido impuesto, que en Chile la dictadura y sus crímenes han sido olvidados y que el tema tiene una presencia marginal en la sociedad, en la medida en que amplios sectores se niegan a hablar de ella.

Moulian lo expresa de la siguiente manera: "Un elemento decisivo del Chile actual es la compulsión al olvido. El bloqueo de la memoria es una situación repetida en sociedades que vivieron experiencias límites. En ellas, esta negación respecto del pasado genera la pérdida del discurso, la dificultad del habla" (Moulian, T: 1997).

Esta idea ampliamente compartida contrasta con la experiencia que puede tener cualquier persona interesada en investigar las cosas que se han dicho sobre la dictadura militar. La literatura chilena cuenta con numerosos textos, de diversas épocas, que relatan la experiencia dictatorial de nuestro país: ya sea bajo la forma de análisis político (Tironi, 1984; Maira, 1988); de investigación sociológica (Moulian, 1997; Huerta, 1993); de análisis económico (Foxley, 1984; Piñera, 1991); de análisis psicosocial (ILAS, 1991; Lira y Piper, 1997(1); (2)), de texto jurídico (Revista chilena de Derecho, 1981); de autobiografía de un narrador o narradora directamente involucrada (Dorfmann, 1998); de poemas (Raúl Zurita, Patricio Manns); de denuncia de las violaciones a los derechos humanos (Vuscovich, 1984; Valdés, 1996); de novelas cuyo contexto sociopolítico es la sociedad chilena bajo el régimen militar (Isabel Allende, Carlos Cerda), etcétera. En estas y otras obras es posible encontrar distinto tipo de descripciones, reflexiones y posiciones respecto de la dictadura. El cine chileno cuenta con numerosas películas (hechas en distintos momentos, dentro y fuera del país), que relatan aspectos diversos de dicho período: De amor y de sombra, Amnesia y otras. Todas ellas circulan comercialmente en formato de vídeo y la mayoría ha sido expuesta en el cine comercial. La música chilena cuenta con diversos grupos y cantautores que han relatado, por medio de la música, la experiencia de vivir en la dictadura (Inti Illimani, Santiago del Nuevo Extremo, Sol y Lluvia, Shwenky y Nilo, Mauricio Redolés, para citar algunos ejemplos).

Podría seguir nombrando diversos ámbitos políticos, académicos y culturales en los cuales se describe, analiza, explica, critica o defiende la dictadura militar. Pero el recuento que acabo de hacer, que muestra sólo la punta del iceberg, permite, al menos, plantearse la hipótesis de que la dictadura ha constituido un tema reiterado en la producción chilena, dato curioso, si se considera la insistencia de algunos sectores en no seguir hablando del tema y la insistencia de otros, que argumenta que las chilenas y los chilenos no hablamos de la dictadura, pues se nos ha impuesto el olvido. 
Por otro lado, cuando se incluye en el análisis las conversaciones cotidianas y discursos del sentido común, es posible encontrar referencias constantes a al dictadura, ya sea a través de palabras o de silencios; de recuerdos o de olvidos. Sostengo que este debate (recordar versus olvidar) produce la certeza de que el recuerdo es una estrategia política eficaz de resistencia frente a la dominación que se expresa a través de su mecanismo de imposición del olvido jurídico e intersubjetivo. Jurídico, en la medida en que la ley de amnistía borra las responsabilidades legales de los represores y, al mismo tiempo, prohibe las investigaciones legales. La resistencia en este plano va por el lado de la denuncia y la demanda de juicio y castigo a los culpables. Es intersubjetivo en la medida en que la resistencia a esta imposición de olvido es el recuerdo, sin importar mayormente el cómo se recuerda, sino más bien el solo hecho de recordar.

Dichas discusiones suponen que la memoria es un depósito en el cual se acumulan algunos hechos que, posteriormente, son traídos a la mente por medio de ese mecanismo llamado recuerdo. Voy a sugerir otra manera de entender la memoria que sigue los aportes del socioconstructivismo radical, del feminismo crítico y de la perspectiva estratégica de las relaciones de poder.

En síntesis, la propuesta consiste en entender la memoria como una forma de acción social (Vázquez, 2001) que produce la realidad que recuerda. Desde esa perspectiva, se hace indispensable analizar los efectos que tiene la manera en que recordamos los acontecimientos del pasado, pues se pueden construir múltiples memorias —de hecho, es lo que pasa- y, aunque no hay una de ellas que sea más correcta que otra, la forma en que hablamos de los acontecimientos juega un papel esencial en su construcción.

Las formas y contenidos de nuestros recuerdos nos producen como colectivos, es decir, producen nuestras identidades y, entre ellas, por supuesto, está la identidad de género. A continuación, voy a explicar en qué consiste entender la memoria como acción social, su relación con las identidades —entre ellas, la de género- También voy a mostrar brevemente los efectos que tiene en la construcción de la identidad de género algunas maneras en que los chilenos y las chilenas recordamos la dictadura.

\section{La memoria como acción social}

A grandes rasgos, los autores que se han dedicado a la memoria desde una óptica socioconstruccionista (Middleton, D. y Edwardes, D., 1992; Shotter, J., 1992; Billig, M., 1992; Iñíguez, L., 1995; Vázquez, F., 2001) plantean que la memoria es una actividad social que construye y reconstruye el pasado a partir del presente, de sus intereses y proyecciones futuras. Se construye a través de prácticas discursivas y comunicativas que le otorgan su valor y significado.

$\mathrm{Al}$ decir que recordamos un suceso, estamos participando en un tipo de relación, generando un marco en el que una afirmación como ésta adquiere signifi- 
cado y es aceptada. De lo que se trata es de producir una demostración argumental y justificativa, incorporando elementos de inteligibilidad y legitimación, de modo que nuestro recuerdo sea verosímil y aceptado socialmente. De este modo, el recuerdo no se corresponde con un pasado pretérito, sino que, al hacer memoria, estamos construyendo una versión del pasado que contiene argumentaciones y justificaciones que la sostienen y legitiman socialmente.

Nuestra forma de hablar sobre los recuerdos es extraordinariamente importante en su construcción. Es, mediante las explicaciones y justificaciones que usamos, que articulamos narrativamente los sucesos desde el presente. El ahora contiene el pasado y el futuro, y éstos sólo pueden ser entendidos en relación al presente. Los futuros posibles o imposibles se arman en el presente, donde se estructuran sus condiciones de posibilidad. De esta manera, los pasados "habitan" en el presente, no sólo en el sentido de que en el presente reinterpretemos estos hechos: es más radical que eso. La idea es que construimos incesantemente el pasado mediante nuestros discursos y nuestras relaciones, mediante nuestros recuerdos y nuestros olvidos. (Vázquez, F., 2001)

El pasado es un tiempo siempre abierto y susceptible de innumerables construcciones, de modo que, cuando hacemos memoria, construimos una de las múltiples versiones posibles. Esto implica que no existe un único pasado, sino que éste es múltiple, ya que está subordinado a las interpretaciones y sentidos que una sociedad le pueda conferir. (Vázquez, F., 2001)

Desde esta perspectiva, no se puede concebir la memoria como una propiedad de las personas, sino, por el contrario, se plantea el recuerdo como nexos que nos vinculan a otras personas. La memoria se constituye en las relaciones sociales y, al mismo tiempo, éstas no tienen sentido sin ella. La memoria se construye en cada relación, mediante la negociación, la dialéctica, la justificación y la acción conjunta. (Vázquez, F., 2001)

Al hacer memoria, las personas y los colectivos construimos nuestra identidad, imagen que, a pesar de los cambios, permite que un sujeto o grupo se reconozca siempre en sí mismo. Los recuerdos nos permiten sabernos parte de un colectivo. Es por esto que no es posible pensar la identidad sin memoria, ya que ella dota de continuidad la imagen de sí mismo a través del tiempo. Tampoco es posible pensar la memoria sin identidad, puesto que la identidad permitirá que la memoria recuerde aquello que no amenaza su integridad.

La memoria, como toda actividad social, se relaciona íntimamente con el lenguaje, ya que no hay recuerdo sin palabras, ni palabras sin recuerdo. Por medio del lenguaje significamos nuestras experiencias: cuando hablamos de ellas es cuando las producimos. Así, las versiones del pasado se hablan, se comparte, se debaten, etcétera y, de este modo, construyen y reconstruyen los recuerdos del presente. La forma superior del recuerdo sería la narración. 
Maurice Halbwachs, sociólogo francés, introdujo el término de memoria colectiva, definiéndola como la memoria de los miembros de un grupo, que reconstruyen el pasado a partir de sus intereses y marcos de referencia presentes (Halbwachs, M., 1950). Esto implica entender la memoria como una actividad social, no tanto por su contenido, como por ser compartida por una colectividad y, sobre todo, por sus funciones de defensa de la identidad grupal, por su carácter normativo y comunicativo.

La memoria colectiva sería un grupo visto desde dentro: cada colectivo se cuenta un cuento, pinta imágenes de sí mismo en el pasado, en el presente y en el futuro, pero siempre siguiendo hilos narrativos que le permiten reconocerse en ellos. De esta forma, la memoria colectiva defendería la identidad grupal al responder a las necesidades y a los intereses del grupo, instaurando un cierto orden social y determinados valores. De aquí se deduce el carácter normativo de la memoria colectiva, pues el rol que jugaría en la construcción de la identidad remitiría a las funciones de legitimación y valoración del orden social y se configuraría como una lección a transmitir sobre los comportamientos prescriptivos del grupo.

\section{La identidad como construcción narrativa}

Ya se habrá notado que, igual que la memoria, estoy entendiendo la identidad como una construcción situada históricamente y producida por las prácticas sociales. Los colectivos construyen su identidad contando historias sobre sí mismos. ¿Puede un grupo o colectivo contar cualquier historia sobre sí mismo? No, y el límite está dado por los marcos interpretativos de nuestra cultura (marcos que, también, nos encargamos de construir). Éstos hacen que algunas historias sean creíbles y otras no, y este es el límite de su viabilidad. La identidad, el sentido de "uno o una misma", correspondería, entonces, a un relato, posibitado por las formas de hablar disponibles en una cultura.

El concepto de identidad narrativa supone que las narraciones no representan la realidad, sino que producen y estructuran el mundo social (Potter y Edwards, 1996). Es decir, que, a través de las narraciones, no sólo describimos, sino que construimos nuestra experiencia en el mundo. Por eso, la narración sería el instrumento para construir nuestra identidad y tendría la función de constituirnos en sujetos o sujetas con significado. Las narraciones nos dicen no sólo quiénes somos, sino que también de dónde venimos y hacia dónde vamos.

Esta manera de entender memoria e identidad permite pensar y articular formas de transformación social. En la medida en que nos dota de la capacidad de re-narrar los acontecimientos, nos permite estructurar nuevos significados de nosotros y nosotras mismas, así como nuevas posibilidades de ser en el futuro. 


\section{Identidad de género}

Hasta ahora, he explicado cómo la memoria contribuye a producir lo que somos, entendiendo, evidentemente, que eso que somos - la identidad - se construye narrativamente. Nuestra identidad de hombres / mujeres / otros no proviene de ninguna esencia natural, sino que es una producción histórica y cultural, que cambia según las situaciones sociales. Igual que la memoria, la identidad se construye en las relaciones sociales locales y cotidianas. Los sujetos y las sujetas -mujeres, hombres u otros- son siempre "sujetas o sujetos en curso", en la medida que despliegan identidades múltiples en función de los efectos concretos que tenga su narración en un contexto determinado.

Las investigaciones y propuestas del feminismo crítico nos muestran cómo nuestro lenguaje cotidiano construye la realidad, no de manera neutra, sino basada en oposiciones binarias, en categorías jerárquicas y desiguales, que primero son nombradas y luego argumentadas como naturales (por ejemplo, la distinción hombre / mujer).

Un eje de esta crítica es que las categorías con las que entendemos el mundo (incluyendo, por supuesto, a nosotras y nosotros mismos y a nuestro "pasado"), no provienen de una supuesta "realidad natural", sino que son una producción cultural que contribuye a producirla y dicotomizarla.

Los movimientos feministas posmodernos nos invitan a develar los efectos que estas categorías naturalizadas tienen en las relaciones de poder y en la vida cotidiana. Un primer paso para esto es entender los efectos de poder que tiene plantear ciertas dicotomías como naturales, problematizando su carácter natural y abriendo así la posibilidad de usar nuevas metáforas que contribuyan a modificar nuestras maneras de relacionarnos.

El problema que enfrentamos cuando construimos una categoría dicotómica es que, en oposición a la afirmación de una identidad, siempre se construye otra en diferencia y asimetría a la primero. Por ejemplo, alguien que es un nohombre, es algo que es hombre en negativo y, por lo tanto, en menos. La categoría víctima lo es en relación a otra categoría: victimario. Quien no es lo uno es lo otro, y no hay más posibilidades.

Cabruja (1996) propone la deconstrucción de las categorías de género, ya que las categorías dicotómicas en que se organiza el lenguaje de la sociedad occidental incluyen un orden del mundo social, que no es neutro, sino que configura elementos de un sistema de desigualdades. En la construcción de una gama de fenómenos referidos al género, se legitima la discriminación de un género en relación a otro, como por ejemplo, las supuestas diferencias entre lo femenino y lo masculino manifestadas en la división sexual del trabajo, así como la idea de que lo femenino corresponde al ámbito privado y lo masculino, a la esfera pública. 
Las identidades de género han sido tradicionalmente consideradas como naturales y no como construidas relacional y sociohistóricamente. El feminismo crítico nos muestra que las categorías hombres / mujeres son productos de las relaciones sociales. Por tanto, si se modificaran dichas relaciones, las categorías mujer y hombre serían susceptibles de modificar. Así, la feminidad y la masculinidad serían prácticas ideológicas que se hacen aparecer como evidencias naturales.

Para Osbome existe un mecanismo típico en las ideologías occidentales que incita a pensar que las relaciones sociales de poder son naturales. Los efectos de la presentación de las mujeres como seres pasivos y de los hombres como seres activos asegura la complementareidad de los sexos en la unión heterosexual. Es así como la defensa del cuerpo y de la maternidad como hechos naturales, que lleva a cabo este tipo de feminismo de la contracultura femenina, separa estas nociones del contexto histórico y cultural y contribuye a reproducir las mismas técnicas ideológicas que han servido al sometimiento de la mujer (Osborne, 1993).

\section{5. ¿Qué efectos tiene contar lo que pasó de la manera en que lo hacemos?}

En los últimos diez años, he participado en numerosas investigaciones sobre memoria, trauma, reparación y derechos humanos. He asistido a innumerables encuentros sobre el tema, he dado cientos de conferencias y participado en otros tantos cursos formales y discusiones informales. En fin, lo que quiero decir es que me la he pasado hablando y, sobre todo, escuchando hablar sobre el tema.

Una de las cosas que me empezaron a sorprender hace un buen tiempo es la paradoja que existe entre la insistencia de algunos sectores sociales por olvidar lo sucedido durante la dictadura - la constante queja de otros sectores que acusan a la sociedad chilena de haberlo olvidado- y lo mucho que hablamos en Chile sobre este tema. Como ya dije antes, eso me llevó a plantearme la hipótesis de que, al parecer, el recuerdo no es una forma de resistencia, como suelen plantear las organizaciones de derechos humanos. ¿Cómo va a ser resistencia frente al orden establecido hacer algo que toda la gente hace, aunque no lo admita?

Entender la memoria como acción social me llevó a investigar las distintas formas de recordar que coexisten en nuestra sociedad, preguntándome por los efectos que tienen esas narraciones del pasado. Evidentemente, no basta con recordar, pero entonces: ¿Cómo construir memorias de la dictadura que contribuyan a subvertir el orden por ella establecido y no a perpetuarlo? He llegado a la conclusión de que las distintas formas en las que recordamos la dictadura cumplen con la función contraria y nos están constituyendo en sujetos y sujetas que no logran resistirse al poder.

Para empezar, podemos hacer el ejercicio de reemplazar el término dictadura (allí donde he hablado de ella) y decir violencia política (es importante el 
apellido), o también podríamos decir violaciones a los derechos humanos, y mantendríamos intacto el sentido. Recordar u olvidar la dictadura es recordar u olvidar su violencia y los crímenes cometidos. Ningún sector propone olvidar las transformaciones económicas, legales o de políticas públicas realizadas por el gobierno militar; aunque también es cierto que quienes las recuerdan ponen el acento en lo violentas que éstas resultaron, mientras que quienes las olvidan insisten en lo beneficiosas que estas transformaciones fueron para el país. Así, violencia-violaciones a los derechos humanos-dictadura, constituyen procesos indistinguibles el uno del otro.

Al narrar los acontecimientos de la historia reciente de nuestro país, el golpe de estado y los diecisiete años de dictadura militar, ocupan un lugar central. El día del golpe es recordado con mucho detalle y relatado desde los afectos y sensibilidades involucradas, constituyéndose en el día de la marca, el momento en que finalizan los meses culminantes del desarrollo de el gran proyecto de transformación del país con el presidente Salvador Allende.

Los discursos constituyen a la violencia-dictadura como un quiebre. En ellos pareciera que la historia de Chile seguía un proceso de evolución y desarrollo constante hacia la paz, la solidaridad y el bienestar. Aunque dicha evolución tenía obstáculos, la clara consciencia que sectores importantes de la sociedad chilena tenían de su sentido, permitía que el camino se siguiese de manera clara y consistente. La violencia-dictadura es producida por los relatos como algo más que un obstáculo, es la gran fractura e interrupción del camino, que vino a alterar el sentido de la historia.

Los discursos le otorgan a la violencia-dictadura una fuerza tal, que ésta parece haber modificado tanto el destino del país, como la manera de ser de las personas de Chile. La violencia-dictadura aparece así como un poder supremo, que habría introducido un sello permanente y determinado en lo que somos como país y como personas. La vivencia de situaciones de violencia nos habría marcado de tal manera que ya nunca habríamos vuelto a ser los y las mismas. Los discursos dividen las identidades (sociales y personales) en un antes y en un después de la violencia-dictadura, y eso se podría constatar en la manera de ser de las nuevas generaciones:

“...yo me voy a poner en la esfera que tú tocaste, que es lo que me pasó a mí, o sea, para mi fue un quiebre tan profundo, esta cosa del 73, este terremoto nacional que tuvimos con el golpe, que en realidad, es decir, me meto muy en lo que estás diciendo, yo tengo cincuenta y no sé si somos generación perdida o qué, pero somos una generación súper vapuleada, en el sentido en que, a mí, con este golpe de estado, este cambio tan profundo, digamos que íbamos para una tendencia y después nos cambian el mono, no por voluntad mía, ni por voluntad de todos los demás, y me zamarreó que me cortó toda mi proyección, o sea, me dejó en blanco, y después de eso empe- 
zar a descubrir, porque no hubo desaparecidos ni muertos, ni cercanos ni lejanos, pero empezar a descubrir el dolor de los otros, qué es lo que significaba una muerte dentro de una familia, lo que significaba un desaparecido, a través de los amigos en todo eso, que me hizo replantearme una actitud que yo tenía antes y después no he vuelto a ser la misma después de eso, ya... y eso me ayudó a tomar decisiones, de dónde trabajar o dónde no trabajar y... hasta llegar hoy en día a tener otra cosa, en el fondo, lo que quiero decir es que me quebró en el fondo, quebró toda una tendencia que yo tenía, y eso significa que nos quebró a todo el mundo, a la familia y qué cambios ha habido en la familia, todo este quiebre, toda esta cosa externa que cambió de todas maneras a cada una de las familias, unos pensaban hacia la derecha, otros pensaban hacia la izquierda, unos vieron el dolor de los otros, otros no lo vieron, las muertes, para algunos, hasta hoy no existen dentro de la familia, entonces como que empezaron a haber como mundos distintos, o sea, como que empezaron a aflorar los mundos individuales $y$ se mantuvieron $y . . . y$, bueno, desde mi punto de vista, es decir, yo era la reaccionaria, otros se adecuaron, se mantuvieron, se metieron en el consumismo, vendedores, es decir, cada cual siguió con su ritmo, pero después de este quiebre, yo no sé qué tan conscientes están del quiebre y qué es lo que le pasó, qué es lo que se quebró, a dónde pensaban ir y a dónde siguieron... (gran y largo silencio)".

"Yo creo que este país hace muchos años que está loco o se volvió loco, no sé en qué momento, quizás en el 73 , yo siento que hubo como un cambio porque yo recuerdo que antes del 73 , la gente, aunque veía el mundo de manera opuesta o distante, podía acercarse... yo vivía en un sector donde vivían muchos sectores políticos desde la derecha hasta la izquierda y la gente compartía, las familias compartian, a pesar de tener visiones opuestas y después del 73 eso se quebró y siento que no nos podemos recuperar, entonces, cada cierto tiempo reaparecen o rebrotan situaciones de violencia $y$ creo que es porque este país no se ha sabido mirar y poder mirarse significa poder reconocer y yo creo que van a pasar muchos años antes de que podamos salir de esto y esa situación me violenta, me produce mucha rabia".

Los discursos producen un clima afectivo de tristeza y nostalgia: por lo que éramos antes y ya no somos, por lo que podríamos haber llegado a ser y no fuimos; por lo que son los jóvenes ahora, a diferencia de los de antes. Se produce un efecto de parálisis, de pesimismo. Ya sea con palabras o con silencios nostálgicos, destaca con fuerza lo que pudo ser y no fue, lo que pudo haber pasado en el pasado y no fue (por el golpe), lo que podría haber sido el presente y no fue (por la dictadura). O sea, un pasado utópico que no ocurrió, un presente que no es lo que debería haber sido y un futuro que ya no fue. 
Las memorias de la dictadura la construyen como un lugar de determinación. Pareciera que si somos ahora más violentos que antes, es porque vivimos la dictadura; que el nuestro es un pueblo más violento que otros, porque vivimos la dictadura; que los hombres son más machistas que en otros lugares, por el autoritarismo impuesto en la dictadura.

Por esta vía, los discursos establecen una relación causal entre pasado-presentefuturo. En el pasado se vivió la dictadura, lo que hace que ahora seamos diferentes (obviamente, peores), y eso que somos ahora nos hace ver el futuro sin mayores perspectivas de cambio. La manera en que estamos construyendo la memora del pasado, nos pone en una situación paradojal: "queremos superar los efectos del pasado que nos produce conflictos, pero son justamente estos conflictos los que no nos dejan superar el pasado" (Tocornal, X.; Vergara, Mª P.; 1988, pág. 172).

Las memorias de la dictadura la constituyen en el acontecimiento de nuestro pasado, que marca nuestra manera de ser y actuar. La dictadura nos habría dañado de tal manera, que no podríamos seguir adelante con nuestra "historia interrumpida", mientras el daño no fuera reparado. Pero esto no puede suceder mientras la sociedad no cambie, y ésta se niega a hacerlo.

El sistema social aparece como inmodificable (los discursos culpan a la dictadura y sus efectos), y así la búsqueda de lo utópico desaparece como ámbito de acción. La pérdida de las ilusiones y las utopías se percibe con un patético orgullo crítico. Situamos la vista en el pasado, construyendo las determinaciones que nos conducen a la inmovilidad en la que estamos. Nos tranquiliza tener el pasado domesticado, y no nos damos cuenta de que es precisamente la inmovilidad con la que vemos esa domesticación nos pone en una situación sin salida. Seguimos hablando de la dictadura como si fuera un ente ajeno a nosotras y nosotros, algo maligno que nos ha transformado en lo que somos. Una ciudadanía traumatizada y apática, sin futuro.

Nuestras narraciones de los hechos del pasado constituyen una forma de acción social, por medio de la cual reproducimos las relaciones de dominación, y las relaciones de género son centrales en este proceso. Los relatos hablan de hombres que ya no son como antes de la dictadura, pero la categoría hombre nunca se cuestiona. Las mujeres ya no somos como antes, ipero seguimos siendo mujeres!

Los relatos que hablan de combates, de actos heroicos, de dedicar la vida a luchar contra la dictadura hablan de hombres. Los relatos que hablan de defensa de los derechos humanos, de salvar vidas (de hombres, por supuesto), de cuidar hijos en situaciones precarias, de sufrimientos y de traumas, hablan de mujeres. No sólo se contribuye a reproducir las dicotomías clásicas de las que ya hablé, sino que también la asimetría y valoración social de estas categorías. 
Los relatos de la dictadura construyen a los hombres-héroes y a las mujeres como víctimas traumatizadas. Las imágenes nos muestran hombres muertos o desaparecidos en combate, versus las viudas vestidas con las fotos de sus hombres-héroes perdidos. Las memorias del sufrimiento son femeninas y las memorias de lo heroico son masculinas.

Muchas veces, los análisis de nuestras y nuestros colegas del mundo de los derechos humanos, nos hablan de lo diferencial de la represión y del sufrimiento especial de la mujer, de su vivencia distinta de la tortura y de las vejaciones (siempre perpetradas por hombres). La mujer sufre por la violación de la intimidad, por la pérdida de sus hijos, de su proyecto familiar. Mientras tanto, el hombre sufre por no poder cumplir con su rol en el espacio público y con sus obligaciones de proveedor. Probablemente, estos análisis son profundamente acertados. El problema es no cuestionar la naturaleza de tal diferencia y detenerse en los efectos reproductores de relaciones de dominación que tiene esa diferenciación.

Las organizaciones de derechos humanos están comúnmente marcadas por simbologías femeninas. Existen las Madres de Plaza de Mayo, ¿y los padres?; están las Abuelas de Plaza de Mayo, ¿y los abuelos? Las agrupaciones de familiares están compuestas mayoritariamente de madres y viudas (sólo no escribo completamente, para no pecar de absolutista) y los hombres participan cuando son hijos y acompañan a sus madres.

\section{Para terminar}

La transformación de las relaciones de dominación de nuestras sociedades pasa por transformar nuestras propias prácticas que son las que las producen, y una de esas prácticas es la memoria. Es esencial reinterpretar el rol de la mujer en la lucha por los derechos humanos y contra la violencia de Estado. Eso permitirá producir nuevas identidades donde lo femenino no sea sinónimo de victimización, sino de lucha.

Creo que es necesario pensar en una manera liberadora de construir nuestros recuerdos. En nuestra forma de relatar los hechos del pasado, pareciera que la dictadura no sólo amarró las leyes, sino que también amarró nuestra memoria. Sin embargo, la memoria es nuestra, la hacemos nosotras y nosotros y, por lo tanto, tenemos que ejercer el poder (y el deber) de transformarla.

\section{Bibliografía}

-Billig, M.: "Memoria colectiva, ideología y la familia real británica", en Middleton, D. y Edwards, D. (comps.): Memoria compartida: la naturaleza social del recuerdo y del olvido. Editorial Paidós, Barcelona, 1992.

-Cabruja, T.: "Posmodernidad y subjetividad: construcciones discursivas y relaciones de poder", en Gordo, A. y Lizana, J. L. (comps.): Psicologías, discursos y poder (P.D.P.). Editorial Visor, Madrid, 1996. 
-Dorfmann, A.: Rumbo al sur, deseando el norte. Un romance entre dos lenguas. Editorial Planeta, Santiago, 1998.

-Foxley, A.: Los experimentos neoliberales en América Latina. Ediciones CIESPLAN, Santiago, 1984.

-Halbawchs, M.: La mémoire collective. Ed. P.U.F., París, 1950.

- Huerta, V.: Los veteranos de los 80. Desde fuera, en contra y a pesar de la institucionalidad. Relatos de vida. Tesis de grado, Escuela de Sociología, Universidad ARCIS, Santiago, 1993.

-Iñíguez, L.: La construcción de la memoria y el recuerdo colectivo: construcción de la memoria como eje de gobernabilidad. Simposium "Cultura, identidad y sistemas políticos”. XXV Congreso Interamericano de Psicología, San Juan, Puerto Rico, 1995.

-Lira, E.; Piper, I.: Reparación, derechos humanos y salud mental. Editorial CESOC, Santiago, 1997 (1).

-Maira, L.: La constitución de 1980 y la ruptura democrática. Editorial Emisión, Santiago, 1988.

-Middleton, D.; Edwards, D.: "Introducción", en Middleton, D.; Edwards, D. (comps.): Memoria compartida: la naturaleza social del recuerdo y del olvido. Editorial Paidós, Barcelona, 1992.

-Moulian, T.: Chile actual: Anatomía de un mito. Editorial LOM, Santiago, 1997.

- Osborn, R. La construcción social de la realidad. Ed. Cátedra, Madrid, 1993.

-Piñera, J.: El cascabel al gato: La batalla por la reforma provisional. Editorial ZigZag, Santiago, 1991.

-Piper, I.: Análisis crítico del discurso psicológico en derechos humanos: una perspectiva psicosocial. Trabajo de investigación presentado en la Universidad Autónoma de Barcelona.

-Potter, J.: Representing Reality: Discourse, Rethoric and Social Construction. Sage Publication, Londer, 1996.

—Revista chilena de Derecho. “Antecedentes de la Constitución de 1980". Volumen 8, 1981.

-Shotter, J.: "La construcción social del recuerdo y el olvido", en Middleton, D. y Edwards, D. (comps.): Memoria compartida: la naturaleza social del recuerdo y del olvido. Editorial Paidós, Barcelona, 1992.

-Tocornal, X.; Vergara, Ma. Paz: Construcción social de la memoria: El régimen militar como un lugar de determinación. Tesis para optar al grado de Licenciado en Psicología. U. D.P., Santiago de Chile, 1998.

-Tironi, E.: La torre de Babel: Ensayos de crítica y renovación política. Editorial SUR, Santiago, 1984.

Vázquez, F.: La memoria como acción social: relaciones, significados e imaginario. Editorial Paidós, Barcelona, 2001.

Vuskovic, S.: Dawson. Ediciones Meridión, Santiago, 1984.

Memorio colectivo y relaciones de género 